\title{
Effective Mentorship to Improve Clinical Decision Making and a Positive Identity: A Comparative Study in Turkey and Portugal
}

\author{
Wilson Correia de Abreu and Seyda Seren Interpeler
}

\begin{abstract}
In some countries there is a growing concern about the shortage of nurses and the students dropping out. Research evidences show the importance of clinical education and mentorship in shaping nurses' identity and promote retention. The purpose of this exploratory study is to compare the mentorship system in two different organizations. Participants were 261 students, 126 from Porto and 135 from Izmir. To gather data a questionnaire was used (CLASI-M). Findings of this study suggest that although nursing students appear to be satisfied with their clinical learning, they have notorious difficulties to understand the meaning of complex care and factors which give rise to complexity. At the end of the study, some specific hypotheses were indicated to be tested in future research. Suggestions are made for improving the quality of the mentorship systems in nursing education.
\end{abstract}

Index Terms-Clinical learning, complex care, mentorship, nursing, quality.

\section{INTRODUCTION}

Despite the official discourse concerning the role and the importance of nursing in the society, there is a contradiction between the way nursing academy looks at nursing education and the students dropping out in many countries. Many countries suffer severe nursing shortage that only can be alleviated by recruiting of nurses from lower middle-income countries. There have been many prominent voices in nursing education that are calling for nurses to progress to higher level of education, to master's and doctoral degrees [1]. Discipline cannot be longer without fully explaining the reasons behind the gap.

Abreu [2], [3] emphasizes the importance of clinical education in shaping nurses' professional identity. Clinical placement provides student nurses with the opportunity to combine cognitive, psychomotor and affective skills, and problem-solving abilities [4]. Students develop their specific knowledge, skills, values, and attitudes that are required for comprehensive health care.

Mentorship is a relationship between two individuals, in which, the wiser, more experienced, teaches a less knowledgeable individual [5]. Mentorship in nursing is a basic form of clinical education of students in clinical field. It provides a dynamic relationship to sharing experience with

Manuscript received November 4, 2013; revised January 22, 2014.

Wilson Correia de Abreu is with the Porto School of Nursing, Porto, Portugal. Rua Dr. António Bernardino de Almeida, 4200-072, Porto (e-mail: wjabreu@esenf.pt).

Seyda Seren Intepeler is with the Dokuz Eylul University (Nursing Faculty), Izmir, Turke -Mithatpasa Caddesi, 35340 Inciralti, Izmir-Turkey (e-mail: seydaseren@gmail.com). the students and providing advice, support and encouragement to them, who have less experience.

Mentorship can be defined also as a support offered by an experienced professional to counsel and guide the novice, having as purpose the personal and professional growth.

Abreu [3] describes the process of mentoring as a succession of interactive stages, in which students are invited to develop an individual and experiential approach to learning. The mentorship process help students to organize and integrate concepts; it provides also students with strategies to develop a better understanding about themselves as caregivers and to promote commitment to the nursing profession. Abreu [2] suggested that the clinical experience combined with mentoring must be actively embraced by nursing to help students to reach a positive self-esteem and create a basis to facilitate changing and motivation to lifelong learning. Abreu [3] later underlines that mentoring leads him or her to begin exploring issues he or she has never questioned. During the mentoring process mentor and mentee share experiences, explore new situations, transfer knowledge to practice and learn to identify priorities to nursing interventions.

Mentorship can have also benefits such as to identify new opportunities for action, to develop comprehensive nursing interventions, to support the reflection, to promote advancement of nurses, to preserve emotional stability, and to develop appropriate ways of coping that reduce psychological distress [6]. Mentorship should be a process of guidance to encourage the students during a traumatic and stressful period [3]; it can reduce the dropping out by offering assistance during the time of transition to the professional life, helping individuals to develop as nurses.

\section{Methodology}

\section{A. Research Question}

The start question of the study was: how do nursing students of two different schools (Izmir and Porto) evaluate mentorship in the clinical placements? Mentor, facing real situations, is a key person in the student's development, conditioning the self-awareness, the self-concept, the self-esteem and the social identity [7].

\section{B. Sampling}

This paper reports the findings of an exploratory and comparative study developed in two academic schools of nursing (Portugal and Turkey). Participants were students from third and fourth years of studies that agreed to participate in the study. A non-probabilistic, accidental 
sample $(N=266)$ was obtained - 126 from Porto (Porto School of Nursing) and 135 from Izmir (Dokuz Eylul University, Nursing Faculty). In both of the countries, nursing graduate course is a 4-year higher education degree program. Even the differences between the curricula of the two institutions, the final profile of competences that is supposed students need to achieve is similar. Rather than hypothesizing direct causal relationships between variables or testing hypotheses, with this exploratory research we tried to get insights into and comprehension of the mentorship process. However, at the end of the study, we intend to develop some specific hypothesis that can be tested in future research.

\section{Data Collection and Analysis}

To gather data, a questionnaire was used - Clinical Learning Assessment Inventory - CLASI-M [8]. CLASI-M is a tool to evaluate the mentoring experience from the students' perspective and includes four different parts. Part one integrates a set of questions to characterize the participants and the clinical settings. Part two is composed by questions to evaluate the context of mentorship, with dichotomous and multiple answering categories. Part three includes an inventory with 24 items, measured with a scale. Participants were asked to rate the value they placed on mentorship on a 4-point scale which includes two extremes of attitude "strongly disagree (very untrue about my mentoring experience)" and "strongly agree (very true about my mentoring experience)". Part four consists of three open questions about significant situations during the clinical training.

The initial results of the Portuguese-language version of the CLASI-M demonstrated its reliability and validity. Internal consistency reliability for the inventory score (alpha $=0.92$ ), was very good, indicating excellent results for initial field-testing. Validity was analyzed using correlations and factor analysis. The results suggested that CLASI-M can be used for assessing mentorship experiences and research purposes. To use CLASI-M in Turkey, content and construct validity were performed.

The questionnaire was translated to Turkish. A multi-step process of forward-translation, back-translation and consultation with experts was conducted. Some parts of the questionnaire were specially analyzed with the authors to provide semantic equivalence. The overall Cronbach's alpha was 0.86. Results support the Turkish version of CLASI-M good psychometric properties for the evaluation of the mentorship process in populations of Turkish students.

Measures were taken to ensure the voluntary participation. Participants were informed about the aims of the study. Complete confidentiality and anonymity were assured, and they gave their consent to participate. SPSS version 16 was used to analyze the quantitative data. Results were explored and analyzed using descriptive statistics. A simple content analysis was undertaken to evaluate the answers to open questions.

\section{FINDINGS}

The majority of the students were female $(94,5 \%)$ and $59,4 \%$ were aged between of 20-22 years. Students were repartee between the third $(49,2 \%)$ and the fourth year $(50,9 \%)$. The students from the two schools are facing different situations on mentorship. In Porto, 94,4\% of them are directly supervised by mentors, under the coordination of a clinical teacher. In Izmir, students are specially supervised by clinical teachers $(57 \%)$, who develop their role in collaboration with mentors. The students from Izmir had more time of supervision; more than $93.3 \%$ of all the students had until 10 direct contact hours with the mentor / clinical teacher; $96,8 \%$ of the Portuguese students underlines that the quality of the information received about the ward previously was good/ very good; the percentage is lower for the Turkish $(87,4 \%)$.

Students were asked to point out what they thought about the overall satisfaction with their experience of mentorship. The percentage of the students that evaluate as excellent or good is higher in Izmir (94,8\% in Izmir and 90,5\% in Porto). Learning to be significant to clients is the major purpose of the educational process in the clinical field. Clients experience transitions along the life cycle but they differ in the way they feel and deal with them. The student is usually a less skilled or less experienced person, with several difficulties to understand these human transitions and decode the amount of information they deal with. This can explain why mentorship is an intense relationship calling for a high degree of involvement and a viable relationship into the individual's professional growth and development. To have a strong and consistent support from a more skilled or more experienced person is a key factor in helping students to feel safe, to explore the environment and to build effective relationships with clients.

As mentioned before, part three of the questionnaire included an inventory with 24 items, measured with a scale. Participants were asked to rate the value they placed on mentorship on a 4-point scale which includes two extremes of attitude - "strongly disagree" (very untrue about my mentoring experience) - and "strongly agree" (very true about my mentoring experience).

As shown in Table I, the majority of students in the two groups reported positive attitudes towards mentorship $(\bar{x}>2)$ :

1) In Izmir, the items with better quotation were: "Since the beginning, the students' responsibilities were well defined" (3,51); "The mentor reflects with the student on their experiences" (3.49) "The mentor gave constructive feedback" $(3,51)$; "The mentor respected the student's level and styles of learning" $(3,50)$;

2) In Porto, the items with better quotation were: "The mentor mediate the relation with the patients" $(3,13)$; "The mentor respected the student's level and styles of learning" $(3,38)$; "The mentor encouraged to overcome difficulties" $(3,32)$; "The mentor was personally kind" $(3,41)$;

3) In Izmir, the item with worst quotation was "The mentor was well prepared for the role" $(2,86)$; in Porto was "The rationale which underpins the practices was discussed with the mentor" $(2,42)$;

Part four of the questionnaire consists of three open questions about significant situations during the clinical training. Even Portugal and Turkey have different cultural, social and demographic characteristics, a set of common realities and principles that underpin the student's clinical experiences were identified. 
TABLE I: EVALUATION OF THE MENTORSHIP PROCESS (AVERAGES)

\begin{tabular}{|c|c|c|c|}
\hline Dimensions & Izmir & Porto & Global \\
\hline $\begin{array}{l}\text { The objectives for the clinical } \\
\text { training are negotiated with the } \\
\text { student mentor }\end{array}$ & 3,48 & 2,86 & 3,18 \\
\hline $\begin{array}{l}\text { The objectives negotiated were } \\
\text { relevant and realistic }\end{array}$ & 3,48 & 3,10 & 3,30 \\
\hline $\begin{array}{l}\text { Since the beginning, the } \\
\text { students' responsibilities were } \\
\text { well defined }\end{array}$ & 3,51 & 3,06 & 3,29 \\
\hline $\begin{array}{l}\text { The mentor reflected with the } \\
\text { student on their experiences }\end{array}$ & 3,49 & 2,80 & 3,16 \\
\hline $\begin{array}{l}\text { The mentor facilitated } \\
\text { opportunities for regular } \\
\text { discussions and feedback }\end{array}$ & 3,3 & 2,94 & 3,13 \\
\hline $\begin{array}{l}\text { Students had a clear } \\
\text { understanding of mentor's } \\
\text { advises and suggestions }\end{array}$ & 3,18 & 3,08 & 3,13 \\
\hline $\begin{array}{l}\text { The mentor gave constructive } \\
\text { feedback }\end{array}$ & 3,51 & 2,81 & 3,17 \\
\hline $\begin{array}{l}\text { The assessment made by the } \\
\text { mentor was focused on the } \\
\text { learning outcomes }\end{array}$ & 3,38 & 2,75 & 3,08 \\
\hline $\begin{array}{l}\text { The rationale which underpins } \\
\text { the practices was discussed with } \\
\text { the mentor }\end{array}$ & 3,34 & 2,42 & 2,90 \\
\hline $\begin{array}{l}\text { The mentor mediated the relation } \\
\text { with the patients }\end{array}$ & 3,11 & 3,13 & 3,12 \\
\hline $\begin{array}{l}\text { Students felt relaxed in the } \\
\text { supervision sessions }\end{array}$ & 3,21 & 2,71 & 2,97 \\
\hline $\begin{array}{l}\text { The mentor supported the student } \\
\text { to make clinical decisions }\end{array}$ & 2,98 & 2,90 & 2,94 \\
\hline $\begin{array}{l}\text { The mentor respected the } \\
\text { student's level and styles of } \\
\text { learning }\end{array}$ & 3,50 & 3,38 & 3,44 \\
\hline $\begin{array}{l}\text { The mentor offered } \\
\text { individualized supervision }\end{array}$ & 3,41 & 2,66 & 3,05 \\
\hline $\begin{array}{l}\text { The mentor's presence motivated } \\
\text { the student during health care } \\
\text { delivery }\end{array}$ & 2,97 & 2,55 & 2,77 \\
\hline $\begin{array}{l}\text { The student always had support } \\
\text { from the }\end{array}$ & 3,10 & 3,01 & 3,06 \\
\hline $\begin{array}{l}\text { The mentor was a good } \\
\text { professional role model }\end{array}$ & 3,22 & 2,97 & 3,10 \\
\hline $\begin{array}{l}\text { The mentor tried to create a good } \\
\text { learning climate }\end{array}$ & 3,25 & 3,10 & 3,18 \\
\hline $\begin{array}{l}\text { The mentor encouraged to } \\
\text { overcome difficulties }\end{array}$ & 3,27 & 3,32 & 3,30 \\
\hline The mentor was personally kind & 3,06 & 3,41 & 3,24 \\
\hline $\begin{array}{l}\text { The mentor was available when } \\
\text { the students were discouraged }\end{array}$ & 3,41 & 3,06 & 3,24 \\
\hline $\begin{array}{l}\text { The mentor and the student } \\
\text { regularly evaluated the } \\
\text { supervision relation }\end{array}$ & 3,15 & 2,87 & 3,01 \\
\hline $\begin{array}{l}\text { The mentor was well prepared } \\
\text { for the role }\end{array}$ & 2,86 & 2,98 & 2,92 \\
\hline $\begin{array}{l}\text { The mentor was committed to the } \\
\text { student's personal growth }\end{array}$ & 3,04 & 2,94 & 3,00 \\
\hline
\end{tabular}

During the process of content analysis, qualitative data was aggregated using to generate synthesised findings based on similarity of meanings. We conclude that the problems, the barriers and the expectations of the students were also similar in the two countries. This is why we present as follows the answers, merging those from the two groups:

1) Situations that were perceived as pleasant: positive feedback from the mentor (or clinical teacher); quality of the support offered by mentor; interactions with nurses from the staff; multidisciplinary work; accessibility of the mentor / clinical teacher; opportunity to discuss real cases and understand human responses patterns; to make decisions and define nursing comprehensive interventions; the increasing autonomy; the learning atmosphere.

2) Situations that were perceived as unpleasant : problems and barriers in communication with the healthcare team; high number of patients to care in the wards by shift; some communication styles of nurses; patient distrust; high number of students in the wards; incompliance of rules to prevent nosocomial infections; the learning activities were very simple and basic; occasional task-centered approach.

3) Situation in which the mentor had a significant role: decision making; to understand human response patterns in real situations, namely those related to psychiatric and chronic diseases; learning to interact with clients; opportunity to examine different alternatives of care; to learn what is a "good nurse" and to be more engaged on the nursing care; understand the meaning of autonomous and interdependent interventions.

\section{DISCUSSION AND CONCLUSIONS}

To develop a meaningful learning, students need to have not only a solid theoretical background but also a bridge between theory and practice [9]. Although nursing students appear to be satisfied with their clinical practices and learning, the overall impression is that students in both schools did not have the opportunity to work with complex situations. To practice safe, beginner-level nursing care, students must have developed some theoretical knowledge and lab work on which they understand the practical transfer of capacities required to implement that knowledge. Simulation techniques in different labs can address the lack of a better preparation for clinical learning, increasing the capacity to deal with complex situations.

General nurses practice in a variety of settings including acute care hospitals, ambulatory care units, nursing homes, health centres or private agencies. Research indicate that new professionals have a set of difficulties to understand the clinical situations and the meaning of complex care and factors which give rise to complexity [10]. Some of these difficulties take place during the graduation and may explain the droop-out.

Mentors are key persons to offer cognitive instructional strategies as a way to help students linking previous ideas with new material, concepts or practices. They need to be able to close the competency gap between nursing school and nursing practice.

Based on the results of this study, mentors should collaborate with schools in the development of transferable skills and competences centred on patient care, such as (among others):

1) Instrumental and cognitive abilities (promote evidence based practice; understand the pharmacologic interventions and implications of medications).

2) Interpersonal competences (develop more interaction with informal caregivers, and conflict resolution).

3) Systemic competences (identify variables relevant to assessment of psychosocial and physical health, understand the pathophysiology as basis of nursing assessment and care, compliance with legal and regulatory issues relevant to nursing practice, 
understand of quality improvement methods, use of systems of information and documentation, develop resilience to manage complex situations).

A good mentor facilitates the acquisition of knowledge and skills, reflecting about values and making appropriate decisions and interventions, to provide safe and effective patient care. Mentor's role has to include tools such as to recognize ethical dilemmas, to know the pathophysiology of patient conditions, to explore alternatives of care, and to develop autonomy and collaboration in practice.

The relationship with mentor undergoing intense experiences can support students' grow and their ability to contribute to the care of clients in complex situations. The new knowledge and skills, developed on the clinical field, is required to provide effective care to patients. Only with basic learning activities, there is a lack of advanced organizers, that means a problem to understand new information and also to completion of complex tasks.

Learning in real situations requires a view that captures the complexity of the clinical world [11]. Perhaps not surprisingly, findings of this study suggest that students have great expectations on the supervisory relationship, learning strategies and support offered by mentors/clinical teachers. Adopting an ecological view, these three main areas aggregated all of the items of the questionnaire:

1) Preparation of the learning process and characteristics of the mentor;

2) Supervisory relationship and decision making in complex situations;

3) Support and positive feedback.

Clinical placement is the best area in which clinical decisions can be taught and developed. Improving the utilization of abstract structures for thinking and the transfer of knowledge to practice, mentors must promote the organization of information into an integrated system that should be the basis of clinical judgments and diagnosis.

Portugal and Turkey are developing national and local strategies to develop mentorship in clinical education of nurses; furthermore, misunderstandings about mentorship still prevail in both countries. Myall, Levett-Jones \& Lathlean [6] claim for the implementation of national standards to clarify the roles and responsibilities of the mentor. In addition to the responsibilities listed above, mentor's role has to include tools such as the capacity to promote the reflexive thinking [12], [13], recognize ethical dilemmas, and work with diversity.

Three predictions can be selected for further testing. Future research should test if and how:

1) Mentorship is associated with a wide range of outcomes, a way to improve the academic adjustment, success, positive behaviours and retention;

2) Mentoring may also have a positive effect on students, fostering psychological attachment to the health context;

3) Mentorship relation can enhance overall well-being, self-confidence, self-esteem and emotional stability.

One of the conclusions reached was that students evaluate as very basic some learning activities. There is a drift at the ideological and conceptual levels that lead to differentiated practice models, with a significant impact on the expected clinical skills or competencies, role descriptions, and participation in decision making. Different concepts about nursing and practices has as result differentiated practice outcomes that lead to some confusion in priorities in nursing care and difficulties about how to be a good nurse.

Among the strategies that appear to be effective to improve clinical education, schools and health organizations could develop dedicated education units that are designed around the mastery of competencies rather than dictating one particular process of education [1].

The possibility of strengthening the largest component of the health care workforce leads to new responsibilities for mentors. Whereas the differences among programs of study in nursing (4-year Bachelor of Science in nursing degree), they have always the responsibility to support students, preparing them for competent professional practice. To expand clinical reach and offer greater security in practice, students should be supported by competent mentors, educated according a National Core Curriculum Framework.

Mentorship and clinical supervision are expected to meet the general standards of care and to develop self-reflective practitioners. The subjects of clinical supervision and mentorship are different. Nevertheless, some supervision strategies are similar. We strongly recommend to setting up in the health organizations integrated systems of mentorship and clinical supervision.

The results from this study cannot be generalized. However, some dimensions identified before can be chosen as variables in further research in this matter.

\section{REFERENCES}

[1] K.-C. Rebecca, Strategies to Produce New Nurses For A Changing Profession, Chicago: Council for Adult and Experiential Learning (CAEL), 2011.

[2] W. Abreu, Identidades, Formação e Trabalho: Da Formatividade à Configuração Identitária Dos Enfermeiros (Estudo Multicasos), Coimbra: Formasau e Educa, 2001.

[3] W. Abreu, Formação em Contexto Clínico: Teorias, Conceitos e Considerações Didácticas, Coimbra: Formasau, 2007.

[4] D. Chan, "Nursing students' perceptions of hospital learning environments-An Australian perspective," International Journal of Nursing Education Scholarship, vol. 1, no. 1, Jan. 2004.

[5] V. Niederhauser, M. Schoessler et al., "Creating innovative models of clinical nursing education," Journal of Nursing Education, vol. 51, no. 11, pp. 603-608, Oct. 2012.

[6] M. Myall et al., "Mentorship in contemporary practice: The experiences of nursing students and practice mentors," Journal of Clinical Nursing, vol. 17, no. 14, pp. 1834-1842, July 2008.

[7] M. Saarikoski, C. Marrow, W. Abreu, O. Riklikiene, and S. Özbicakçi, "Student nurses' experience of supervision and Mentorship in clinical practice: a cross cultural perspective," Nurse Education in Practice, vol. 7, pp. 407-415, Aug. 2007

[8] W. Abreu and T. Calvario. "Learning in clinical settings: The perspective of the students," Teoria, Vuskum a Vzdelavanie $v$ Osetrovatel'stve, Bratislava: Comenius University, pp. 198-209, 2005.

[9] L. Johnson, M. Cohen, and M. Hull, "Cultivating expertise in oncology nursing: methods, mentors, and memories," Oncology Nursing Forum, vol. 21, no. 8, pp. 27-34, Sep. 1994.

[10] A. Akyuz, N. Tosun, D. Y1ldiz, and A. K1lıc, "Reflection of the nurses on their responsibilities and the students' working system during clinical teaching," TSK Koruyucu Hekimlik Bülteni, vol. 6, no. 6, pp. 459-464, 2007

[11] P. M. Ironside and A. McNelis, "Transforming clinical education," Journal of Nursing Education, vol. 50, no. 3, pp. 123-124, Mar. 2011.

[12] W. Abreu and C. Marrow, "Clinical supervision in nursing practice: a comparative study in Portugal and the United Kingdom," SANARE Políticas Públicas, vol. 11, no. 2, pp. 16-24, Dec. 2013.

[13] H. Nasrin, P. Soroor, and J. Soodabeh. "Nursing challenges in motivating nursing students through clinical education: A grounded theory study," Nursing Research and Practice, vol. 2012, June 2012. 


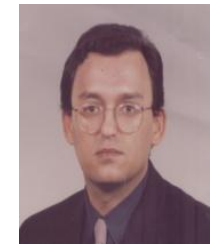

Wilson Correia de Abreu earned his $\mathrm{PhD}$ in education with an emphasis in adult education at the University of Lisbon in 1999 and the master in education sciences in 1994, at the same University. He earned also the Aggregation in Health Sciences in 2006 at the University of Aveiro. Wilson is a senior member of the International Economics Development Research Center (IEDRC).

Wilson is a full professor at the Porto School of Nursing, where he coordinates the Master Course on Mental Health and Psychiatry. In the last years, he has collaborated with Universities and other organizations, teaching anthropology, clinical supervision, psychiatry and qualitative methods. International experiences (research and teacher mobility) included European countries and Brazil, USA, Canada, Turkey and Russia.

During his professional life, Wilson presented more than 150 conferences in Portugal and abroad and was a member of European Projects (European Networks, Leonardo da Vinci, Grundvig). He collaborates with the University of Porto, Lisbon, Aveiro, Azores and Évora advising and examining $\mathrm{PhD}$ thesis. Three of his books are known worldwide ("Health, illness and cultural diversity"(Lisbon: Editora Piaget: 2003, 2013 - 2 editions), "Transitions in multicultural contexts" (Coimbra, Formasau: 2008, 2011 - 2 editions) and "Education and learning in clinical context. Fundamentals, theories and didactic considerations" (Coimbra, Formasau: 2007). The author's major fields of studies include mental health and psychiatric disorders (dementia, depression, and suicide), clinical education, clinical supervision and anthropology of health

Professor Abreu is actually the President of the Board of Curators of the Polytechnic Institute of Portalegre, a member of the Scientific Commission for Doctoral Studies in Nursing (University of Lisbon), a collaborator of the Agency for Assessment and Accreditation of Higher Education (A3ES) (Portugal) and also a member of ASMELP (Mental Health and Psychiatric Association of the Portuguese Speaking Countries).

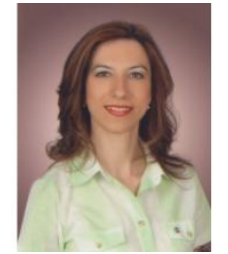

Seyda Seren Intepeler earned her $\mathrm{PhD}$ in management at the Institute of Health Sciences Istanbul University in 2005 and completed her Master in the Department of Nursing Management at the Institute of Health Sciences Dokuz Eylul University (Izmir). She finished her postdoctoral fellow program at McMaster University (Canada-Hamilton) in 2009.

Seyda is an associate professor at the Dokuz Eylu University (Nursing Faculty), where she coordinates the Master and Doctorate Course on Nursing Management. In the last three years, she has collaborated with Dokuz Eylul University Hospital (nursing students' clinical education) and preceptorship program for nurses. The international experiences included Portugal (Thematic European Nursing Network (TENN) and Romania (teacher mobility).

During her professional life, Seyda presented approximately 100 conferences and poster presentations in Turkey and abroad. She was a member of several European Projects (European Networks) and advisor of 20 master and PhD thesis. Seyda has 35 publications in SSCI, SCI, SCI Expended and national peer-reviewed journals. The author's major field of studies and research interests includes problem based learning, preceptorship programs, patient safety issues, medical error, reporting system in medical error, quality of care.

Associate Professor Intepeler is actually a member of the Faculty Board and ethical committee in the Institute of Health Sciences, a member of the Scientific Commission for Master and Doctoral Studies in Nursing (Dokuz Eylul University in Nursing Faculty), a founding member of the Agency for Assessment and Accreditation of Nursing Program (Turkey) and also a member of Turkish Nurses Association, Nursing Education Association and Nursing Research and Development. 